\title{
Biophysical Reviews' "Meet the Editors Series"—a profile of Kuniaki Nagayama: encounters and leaps in a transborder journey through biophysics
}

\author{
Kuniaki Nagayama ${ }^{1,2}$ \\ Published online: 4 March 2020 \\ (C) International Union for Pure and Applied Biophysics (IUPAB) and Springer-Verlag GmbH Germany, part of Springer Nature 2020
}

\section{Abstract}

In this second instalment of the Biophysical Reviews' Meet the Editors Series we hear the story of Prof. Kuniaki Nagayama, one of the five Executive Editors of Biophysical Reviews.

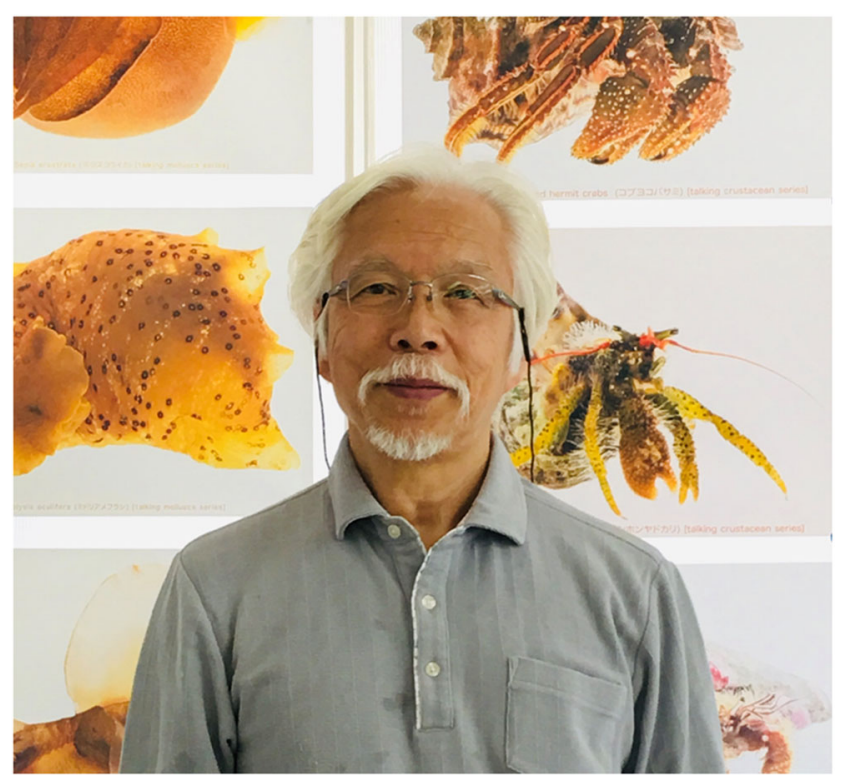

In front of exhibition panels showing small sea creatures

In my role as Executive Editor of Biophysical Reviews, I have been asked to provide a short description of my life and research for the readers of Biophysical Reviews. I have tackled this request in roughly chronological order.

Kuniaki Nagayama

nagayama@nips.ac.jp

N-EM laboratories Inc., Hongo 5-5-6-402, Bunkyo, Tokyo, Japan

2 Science Communication Research Institute, Minamiota 1-11-13-417, Yokohama, Japan

\section{Boyhood (1950s)}

Science fiction poet Ray Bradbury has a short story collection $S$ Is for Space. It was a collection of his masterpieces from the time when Sputnik's photographs were all over the newspapers and everyone dreamed of future adventures in space. In my boyhood, not only space but science also held a rosy dream and future. Looking back on those days, I feel like I was aspiring to science in a natural way following the trends of that era. However, boys cannot distinguish between science and technology. Edison was the scientist by whom I was most impressed among those I met through the world of scientific biographies. The presented vision of Edison (probably adapted from biographers and different from the real image), was, for me, at that time, what constituted a true "inventor"indeed to my young mind, science was invention. My passion for inventions distinguished my elementary school days. Summer vacations had to be always the season of invention. Devising teaching materials used in science classes and providing them to the class teachers satisfied my inventive spirit. I also learned at that time that there was sweet temptation of appreciation of my teachers and praise of my friends for each deed of invention.

\section{Adolescence (1960s)}

When did the end of boyhood come? It is clear that it did not come suddenly one day, but recalling the past, I think it was from the second year of junior high school. I encountered Gauss, a great mathematician through reading about his approach to the famous addition problem from 1 to 100. Maybe you have read about it in a biography about Gauss. 
Immediately I was fascinated by mathematics and mathematical thinking. Here, there was a world of science and intellect different from craftsmanship and technology, a world of reasoning that cannot simply be mastered by trial and error. The mighty Edison, whose feats I so longed to emulate, had disappeared from my mind before I realized it. This direction was further strengthened by the encounter with a physics teacher during my first year at Takasaki High School. He demonstrated how to solve the difficult acceleration problem in force very easily. I was informed that there was some magic called "differentiation" behind the problem. I came across a concept of "physics" that I had never imagined. My reverence to the academic studies of physics sprung up upon realizing the existence of so pleasant a partnership between mathematics and natural phenomena.

In my first year at the University of Tokyo, I passed through the barriers that everyone in science and technology should pass, $\varepsilon$ (small amount) and $\Delta$ (small change), and realized that it was time to go on to major in the third grade. Apparently, there is something interesting about disciplines other than science. Modern economics seem to have a lot to say and do, and the neural system seems so interesting. Indeed in both cases, it seems that the differential equation can describe a number of "laws." But, after all, I did not have any chance to meet influential seniors or teachers in these fields. Instead I chose physics as my major. After 2 years of physics training, the graduate school was waiting. The jewel of physics in the 1960s was elementary particle physics. However, the teachers warning that "elementary particles cannot eat rice" and the inner whisper of "too far away from humans" made me choose the most "human" discipline, biophysics. In 1968, I joined the Akiyoshi Wada Laboratory at the Department of Physics, The University of Tokyo. It was here that I first met real science.

\section{The heyday (1970s-1995)}

To tell the truth, I have been supervised by Prof. Wada for more than 50 years. At the beginning of the 1980s, we cochaired a research group called "Measuring Life" sponsored by a Science and Technology Association. Indeed it was this measuring life group which decided my research style. In short, "Biometrology (molecular-level Biometrics)" is a suitable condensed summary of the 50-year history of my research life. In order to measure life precisely, you have to make a measuring sword. It was Prof. Wada who told me that there was science in the invention of biophysical tools. After the rigors associated with 5 years of $\mathrm{Ph}$. D. course, I returned to the admiration that I had for Edison in my boyhood. After all, invention became meaningful again. Moreover, beyond my boyhood, I learned that a discovery in science could be led by an invention of novel rulers or measurement tools.
Good seniors will show you the way. My second important encounter to come through the medium of the written word was in a dissertation subscription seminar led by Yuzuru Fushimi; the author in question was Richard Ernst of the Federal Institute of Technology Zurich (ETH). My encounter to the Ernst Nobel Prize-winning paper on the pulsed FT NMR [Ernst and Anderson 1966] determined the next 25 years of my research life. A unique technology of "measurement" had emerged as a science linked to the mathematical theory of FT (Fourier transform). The connection between Edison and Gauss became a form, a substance, and a manifestation. I discovered such a subject that I could do best and survived my graduate school days studying NMR.

In the summer of the second year of graduate school (1972), I was in Moscow for a presentation at the International Conference on Biophysics. The conference overwhelmed the audience with Oleg Jardetzky keynote lecturing on his NMR research on deuterated nuclease, which was said to have cost a million dollars at the time. Kurt Wüthrich was there, listening to my Ph.D. work [Nagayama and Wada 1972] (Fig. 1), which was covered in Nature [News and Views 1973]. This paper later led me to 3 years of study abroad in Zurich, and 5 years later, I did compete with Jardetzky in two-dimensional (2D) NMR development. While I still fondly recall that summer of travel through middle Asia following the international conference (and accompanied by my colleague, Hidekazu Hayashi), I could never forget my fateful encounter with Wüthrich.

Despite having the good luck to be employed as an Assistant Professor at the Wada Laboratory immediately after the graduate school, the handicap was that I did not have my own freely usable NMR system. Meanwhile in 1975, Wüthrich sent me a letter from ETH. It was an invitation to join him in a project to apply 2D NMR to proteins, which was planned to start from 1976 with Richard Ernst. Of course, I fell into raptures over it, as I could go to ETH where Ernst was leading a NMR group and I would work with him, which had been my long-standing dream. Then anxiety surged. What is 2D NMR? The draft of a paper sent from Wüthrich, which had been accepted later [Aue et al. 1976] and finally awarded to the Nobel Prize in Chemistry, was like a rare form of Chinese text. Anxiety about foreign countries and incomprehensible physical concepts overlapped. However, Ernst's attraction won, and I landed in Zurich as the first postdoc of the first Ernst-Wüthrich joint project in November of 1976. Following my arrival, research work between Ernst, Wüthrich, and I went ahead in leaps and bounds for 3 years. Details are given in references [Nagayama et al. 1977; Nagayama et al. 1978; Nagayama et al. 1979; Nagayama 1979; Nagayama et al. 1980; Nagayama and Wüthrich 1981].

After returning from Switzerland, my seemingly perpetual quest for usable NMR equipment continued. Fortunately, the Institute for Protein Research at Osaka University was 


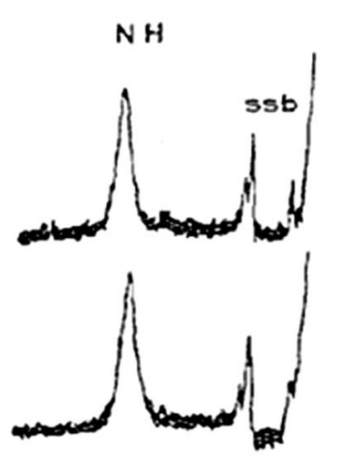

$\%$ TFA

2.0
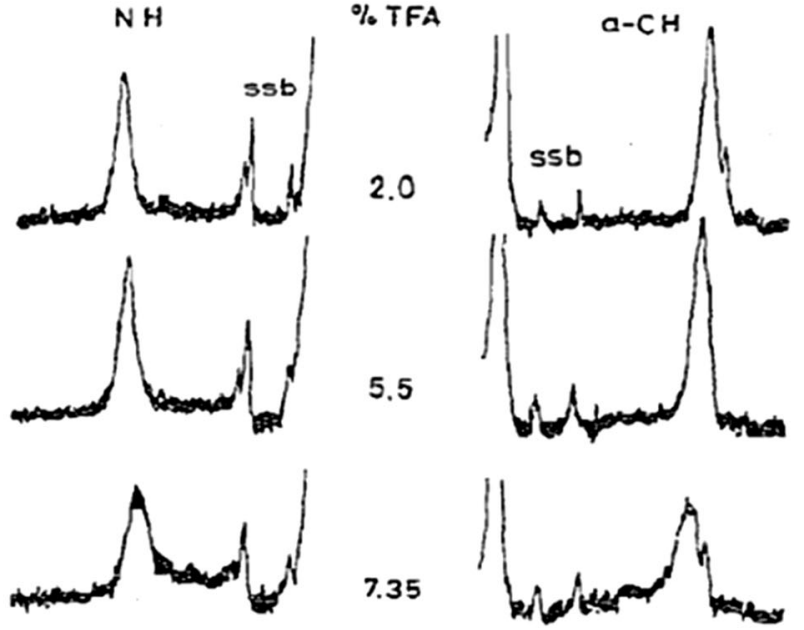

7.35

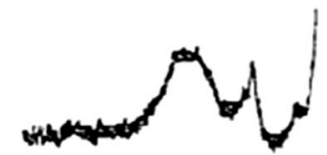

8.9
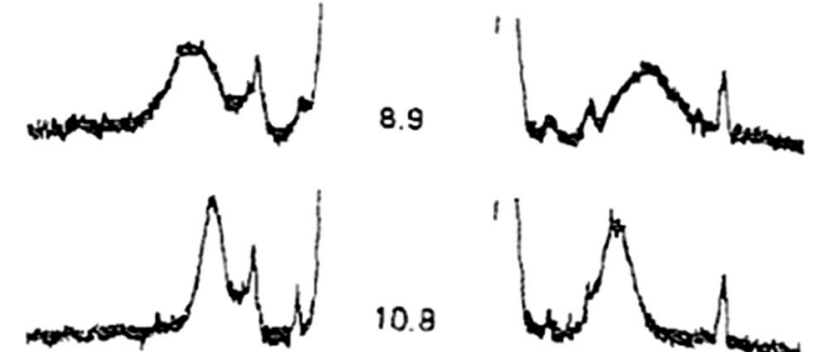

10.8
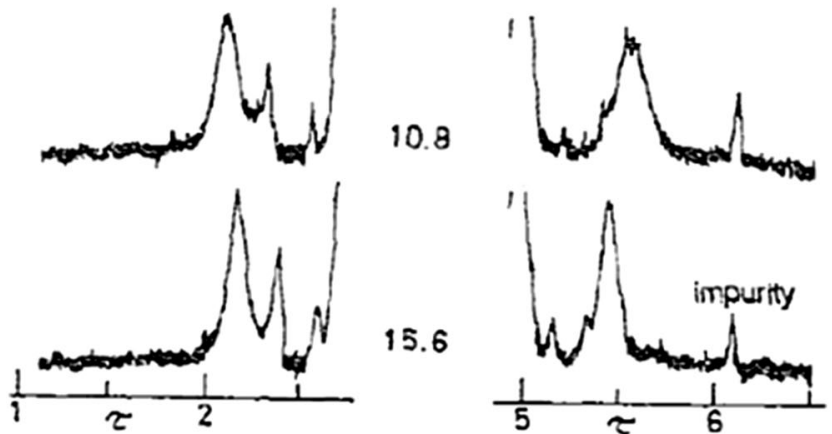

15.6

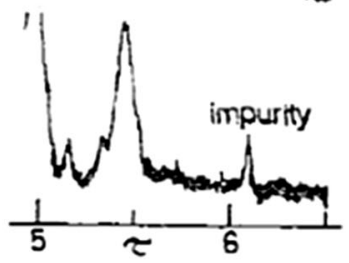

Fig. 1 A NMR spectrum that fixed the controversy in the NMR community in the 1960 s to 1970 s on the helix-coil transition rate problem [Nagayama and Wada 1972]. Refer to News \& Views, Nature 243: 186187 (1973) for details

opening devices for collaborative researchers, and they made a position available to me for 4 years. During this time, I was able to continue the development and application with 2D NMR and was successful to have the NMR community in Japan become convinced of its capability in biophysics [Nagayama et al. 1983]. However, as I had been an Assistant Professor in the Wada laboratory for more than 10 years, I felt it was time to leave the University of Tokyo in any way and began to look for the next workplace. Bruker Ltd., the NMR production company familiar to me in my experiments in Switzerland, offered me the position of the Far East Manager, but I eventually transferred to JEOL Ltd. on the condition that a new laboratory, Biometrology Laboratory, was settled for me. For 10 years, I could enjoy the development of 2D NMR without the restraint on lack of equipment that I had once experienced. Importantly it was at this time that I had the privilege to work together with such young geniuses as Toshimichi Fujiwara [Fujiwara and
Nagayama 1985; Fujiwara and Nagayama 1988; Fujiwara and Nagayama 1991; Fujiwara et al. 1993] and Toshio Yamazaki [Yamazaki et al. 1991; Yamazaki et al. 1993; Yamazaki et al.]. I fondly recall the excitement of research during this period and the breathtaking tension at that moment when I challenged ETH for a competition in heteronuclear 3D NMR development [Nagayama et al. 1990]. However, despite our efforts, the ETH school won that competition, and all achievements were credited to them. Such stories represent a hard truth in science - the history of science is often represented in the name of just one or two individuals at the end of a long race. However, there was no objection to the 1991 and 2002 Nobel Prize in Chemistry being given to two seniors, Ernst and Wüthrich, with whom I enjoyed working closely with in the beginning of my thirties.

In the late 1980s after the NMR race, I was trapped by a feeling of weakness. I tried to seek an outlet toward a completely different field, and, partly due to luck, I was able to lead a huge national project, the ERATO Protein Array Project supported by the Science and Technology Agency between 1990 and 1995 [Yoshimura et al. 1990; Denkov et al. 1992; Kralchevsky et al. 1992; Denkov et al. 1993; Kralchevsky and Nagayama 1994; Adachi et al. 1995; Dimitrov and Nagayama 1996;]. During that time, I moved from JEOL to the University of Tokyo (Komaba campus), and NMR became a thing of the past. Nevertheless, neither the technical innovation of protein arrays nor the education in Komaba satisfied my scientist soul. Meanwhile, another encounter came. And the next leap was born.

\section{Matured period (1995 )}

I think it was in the late 1995 when an aged gentleman visited my room in Komaba. It was Dr. Kiyoshi Hama, the director of the National Institute for Physiological Sciences (NIPS) in Okazaki. He remembered my collaborative works done with Teruhiko Toyo-oka [Toyo-oka et al. 1986; Toyo-oka et al. 1987], a physician at the medical school of the University of Tokyo around 1985, a medical NMR study on rat heart. He intended to confer the professor position of MRI study on me, but since my mind was far away from NMR, I spoke a completely different research idea to him, a molecular physiology, namely, analyses of intracellular protein structures by cryo-electron microscopy (EM). It turned out later to me that Dr. Hama was one of the pioneers of ultrahigh-voltage EM, which had breathed new air into neuroanatomy [Hama 1959]. A perfect EM layman told an ultra EM expert about his dream with EM, so he might have been quite amazed. I probably exhaled my gloominess to my future teacher. After a short while, I was invited to NIPS for a post of professorship and encouraged to start an EM laboratory by Hama, who actually 
supported me by guaranteeing a huge budget for the world's best electron microscope of JEOL $300 \mathrm{kV}$ at that time.

If there is "God of science," how many times will he smile at a scientist in his life? It was on a super-express train (Shinkansen) heading from Tokyo to Okazaki in December 1997 that his greatest smile beamed down upon me. This was the moment of the revelation of a metrological idea called "Complex Observation of Electron Waves", a complete measurement method for recovering amplitude and phase of electron waves (refer to Fig. 2). The details are left to the papers published from 1999 to 2011 [Nagayama 1999; Danev and Nagayama 2001a; Danev and Nagayama 2004; Hosokawa et al. 2005; Nagatani and Nagayama 2011], but I cannot forget the feeling of floating after the revelation. It is a feeling that I was the only person to reach this truth in the world.

The development of phase-contrast electron microscopy started with the need to realize this complex observation EM. Since complex observation is an observation of the original complex amplitude for electron waves and can be realized by a complex combination of the normal one yielding the real part and the phase contrast one corresponding to the imaginary part, the development of the phase-contrast method, which had been incomplete at that time, was inevitable. Fortunately, in 1998, Radostin Danev (from Bulgaria) enrolled in the Graduate School of Physiological Sciences at SOKENDAI and so the development could get smoothly started. The phase-contrast method using a Zernike phase plate had a performance much better than expected [Danev and Nagayama 2001a] with the $300 \mathrm{kV} \mathrm{EM}$, which was a treasure machine able to be introduced with the aid of Hama. However, Danev and I soon painfully recognized that it was beginner's luck, even though the Zernike phase-contrast paper of 2001 has frequently been cited as a classic [Danev and Nagayama 2001b]. A huge barrier to reach the perfect phase-contrast method, which had been unsuccessful for nearly 50 years, stood before us. This was the "phase plate charging problem."

In short, development of phase-contrast EM depends upon the development of a technology for avoiding the charging of phase plates. The three main factors affecting the charging phenomenon are (1) conductivity of the material consisting the phase plate, (2) contamination on the phase plate surface, and (3) differences in the phase plate shape (specifically, Zernike phase plate or Hilbert phase plate). Workarounds for the three factors are (1) the use of a conductive light element as the phase plate material, (2) the application of various cleaning techniques including a carbon film rapping to embrace contaminants, and (3) preferential use of the Hilbert type of phase plate as being easier to avoid charging [Danev et al. 2002; Kaneko et al. 2005; Kaneko et al. 2006;]. A long-life phase plate can be obtained only by integrating these three measures. A fairly fine technology for making antistatic phase plates was gained in 10 years of development from 2001 to my retirement year (2011), and high contrast EM images could be routinely

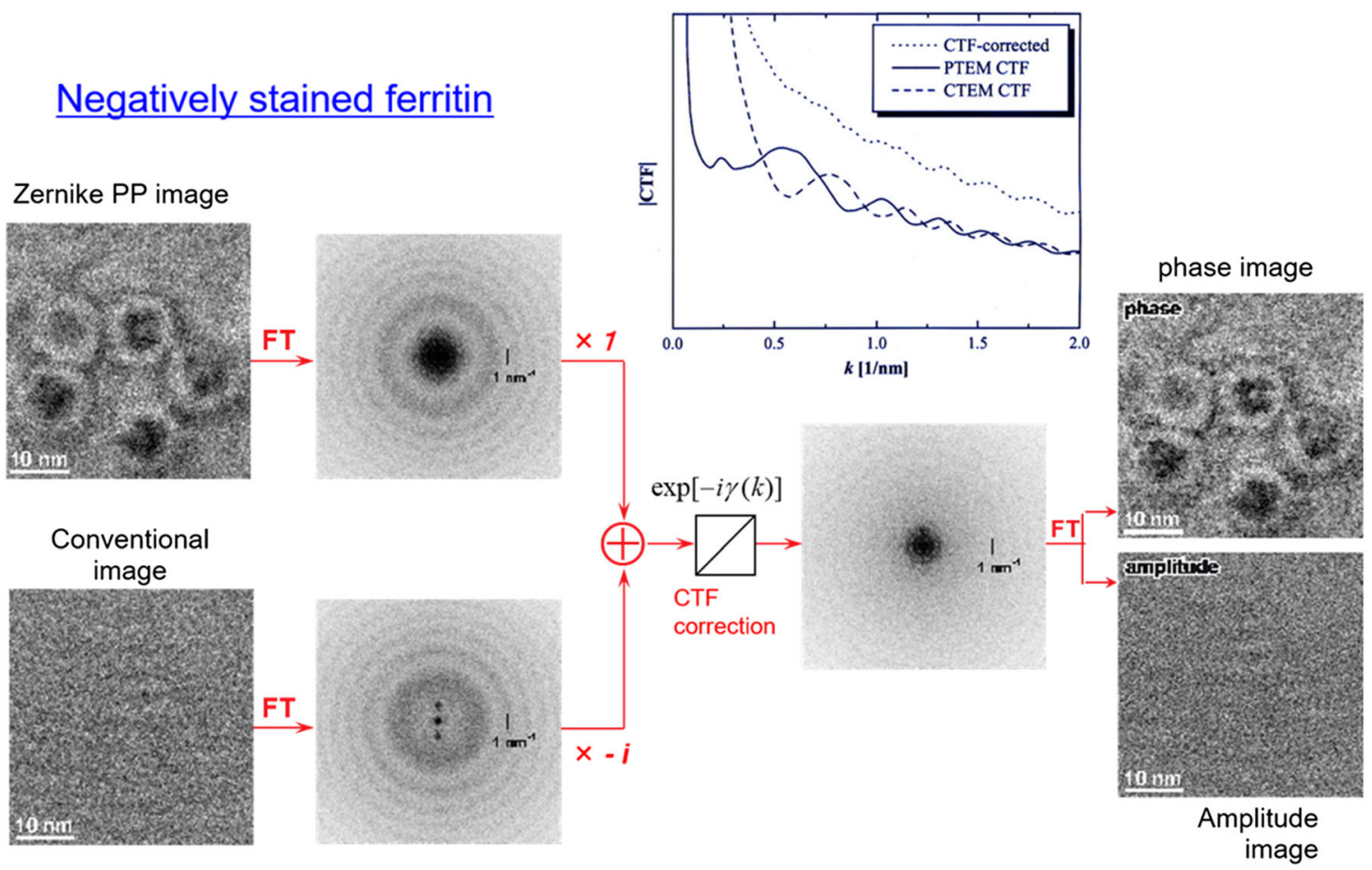

Fig. 2 From the paper [Danev and Nagayama 2001a] that proved the effectiveness of complex observation in EM. The pure phase and pure amplitude image are obtained through a complex image virtually made in computer with a complex combination of the conventional and Zernike phase plate image 
obtained for various biosystems [Shimada et al. 2007; Danev and Nagayama 2008; Yamaguchi et al. 2008; Danev et al. 2010; Rochat et al. 2011; Fukuda and Nagayama 2012; Dai et al. 2013], but it was not completed in terms of extending the life of phase plates. Then, in 2014, Danev proposed a Volta phase plate that fixed the issue of phase plate life with the reverse idea of using charging itself [Danev et al. 2014] and tentatively completed it.

Before leaving Okazaki, where I had been till the retirement age, I undertook two EM innovations in parallel with the development of phase-contrast EM. Those were a photon/ electron hybrid microscope where a light microscope and an electron microscope are truly combined in one device and a $500 \mathrm{kV}$ linear accelerator transmission electron microscope (Linac-TEM) that combines a linear accelerator, a linear decelerator, and a TEM. The former is a new microscope that can simultaneously observe the same field of view of a sample with photon and electron [Iijima et al. 2014; Nagayama et al. 2016] and is different from the CLEM (Correlative Light and Electron Microscope) that off-line combines separated optical and electron microscopes. The $500 \mathrm{kV}$ Linac-TEM is a revolutionary technology that enables the miniaturization of ultrahigh-voltage TEM by replacing the DC accelerator of a normal EM with an RF accelerator [Sannomiya et al. 2019]
(Fig. 3). Development of the $500 \mathrm{kV}$ Linac-TEM was a real technological challenge and three colleagues, Yoshihiro Arai, Yukinori Nagatani, and Takumi Sannomiya, had to spend 10 years to complete it. Fortunately, it attracted the media attention and has been highlighted in Nature [Research Highlights 2019]. The first (Fig. 1) and last (Fig. 3) work in my 50-year academic life are both coincidentally underlined by Nature.

\section{Endless transbordering journey (2014 )}

The God of science would never smile upon me again, or so I thought, but 5 years after retirement, after turning 70 years old in 2016, he indeed did smile once more. This time it involved the discovery of the four-dimensional reciprocity theorem in electron microscopy. Leveraging this theorem, I realized that I could convert a 4D STEM into a 4D TEM, and again, the floating feeling once encountered when I discovered the complex observation came back to me. Moreover, it led me to expect that the 4D TEM had the potential to improve sensitivity over the 4D STEM. The biggest challenge in biological EM, which has an electron dose limit due to material destruction, has always been in the sensitivity improvement.

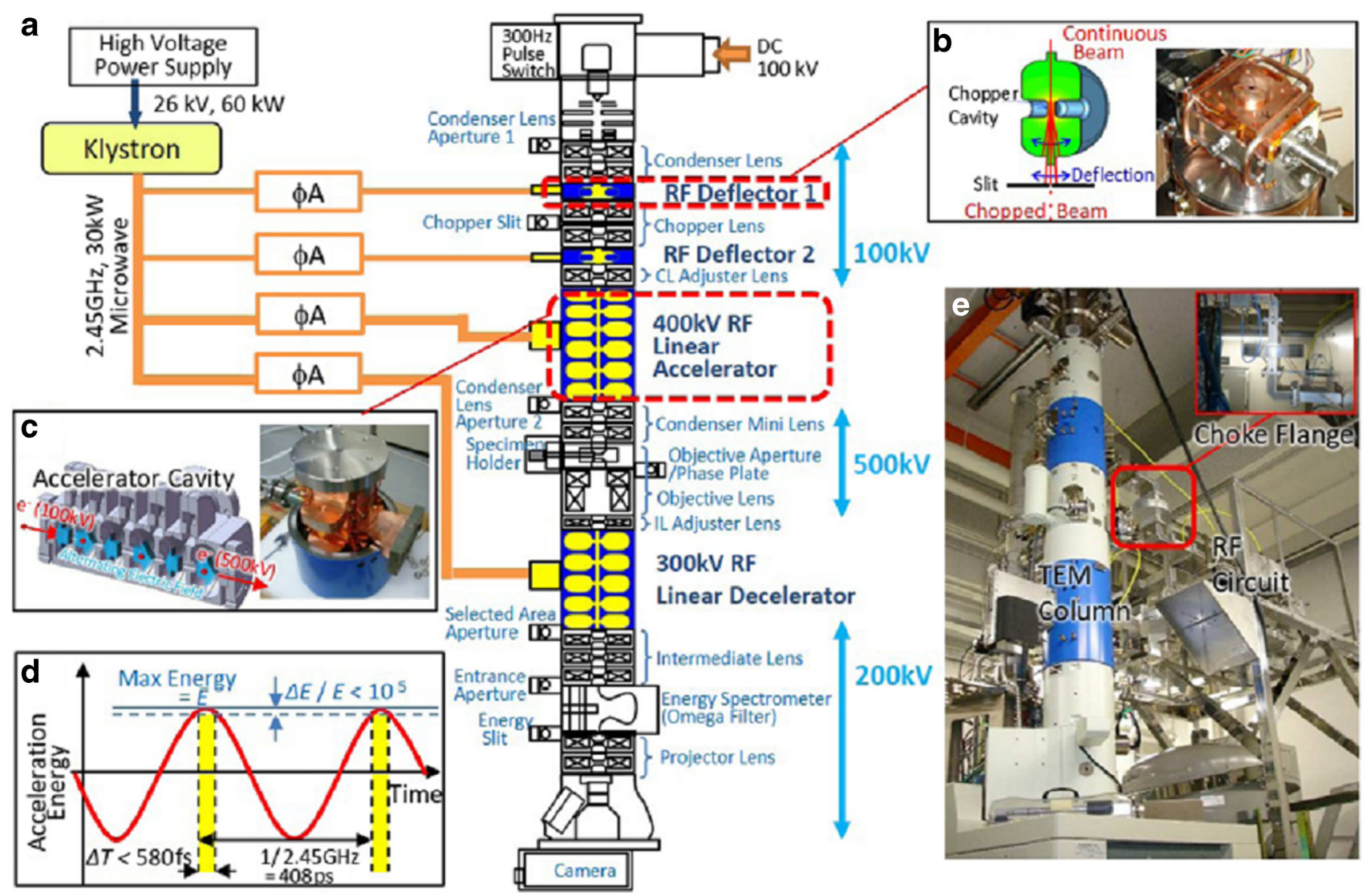

Fig. 3 From the paper [Sannomiya et al. 2019] that demonstrated the feasibility of the high-resolution Linac-TEM at an ultrahigh voltage. Refer to Research Highlights, Nature 574: 456-456 (2019) for details 
Expectations that deepening the 4D TEM may open up new innovations in sensitivity to biological EM have evoked the inner voice, "Stop the easy life after retirement and return to an active research life.".

Here I will open the secret of my academic transbordering. In my twenties, I met Ernst's pulsed FT NMR and was fascinated by the bottomless power of the Fourier transform. Since then, I have been trying to be a good user of FT, and thanks to that I was able to have an open fight with $2 \mathrm{D}$ NMR and 3D NMR. My decision to transborder from NMR to EM was also guided by the FT relationship between images and diffractions in EM. Crossing the border was not necessarily a pain as turning to EM meant FT optics to me. However, the discovery of the 4D reciprocity theorem and 4D TEM meant that I had to meet the limitations of FT optics. The challenge of jumping from the conventional 2D TEM to 4D TEM could not be overcome with the FT sword. After more than 2 years of twists and turns, I met the Wigner distribution function (WDF).

In 4D microscopy, an image is observed in a form of 4D function integrating the real and reciprocal space. On the other hand, WDF is based on a $4 \mathrm{D}$ space that combines the real and reciprocal space. The compatibility of both seemed to be good. In FT optics, two 2D functions that are expanded in the real and reciprocal space, respectively, are used, while the WDF treats both in an integrated form in a 4D space. My intuition that here was something new was probably due to my successful experience in leaping from 1D NMR to 2D NMR. I was rather willing to take the struggle associated with the leap from 2D to 4D in TEM. Two years later, in 2018, I was able to find a master equation that could guide $4 \mathrm{D}$ microscopy with a WDF formulation. It is opening a rejuvenation from Fourier optics to Wigner optics [Nagayama 2020] and has opened a venture, N-EM Laboratories, in Tokyo in February of 2019.

As one of the aged trying to pursue the 100-year research life, looking back on the past is not to be encouraged. Nevertheless, I did not decline to contribute to Biophysical Reviews upon a request for a "Meet the Editor" piece. If I could make any scientific contributions, as I have here described, it was because I could have so many joyful encounters with enlightening people, including those I could not describe here due to the page limitation. They pushed me to go a step further toward something resembling a leap. Particularly I owe a great debt to Dr. Hama, who passed by last year leaving me the irreplaceable discipline of electron microscopy. I would like to dedicate this essay to the late Professor Hama.

\section{References}

Adachi E, Dimitrov AS, Nagayama K (1995) Stripe patterns formed on a glass surface during droplet evaporation. Langmuir 11:1057-1060
Aue WP, Bartholdi E, Ernst RR (1976) Two-dimensional spectroscopy. Application to nuclear magnetic resonance. J Chem Phys 64:2229 2246

Dai W, Fu C, Raytcheva D, Flanagan J, Khant HA, Liu X, Rochat RH, Haase-Pettingell C, Piret J, Ludtke SJ, Nagayama K, Schmid MF, King JA, Chiu W (2013) Visualizing virus assembly intermediates inside marine cyanobacteria. Nature 502:707-710

Danev R, Nagayama K (2001a) Complex observation in Electron microscopy. II Direct Visualization of Phases and Amplitudes of Exit Wave Functions. J Phys Soc Jpn 70:696-702

Danev R, Nagayama K (2001b) Transmission electron microscopy with Zernike phase plate. Ultramicroscopy 88:243-252

Danev R, Nagayama K (2004) Complex observation in Electron microscopy. IV Reconstruction of Complex Object Wave from Conventional and Half Plane Phase Plate Image Pair. J Phys Soc Jpn 73:2718-2724

Danev R, Nagayama K (2008) Single particle analysis based on Zernike phase contrast microscopy. J Struct Biol 161:211-218

Danev R, Okawara H, Usuda N, Kametani K, Nagayama K (2002) A novel phase-contrast transmission electron microscopy producing high-contrast topographic images of weak objects. J Biol Phys 28: $627-635$

Danev R, Kanamaru S, Marko M, Nagayama K (2010) Zernike phase contrast Cryo-Electron tomography. J Struct Biol 171:174-181

Danev R, Buijsse B, Khoshouei M, Plitzko JM, Baumeister W (2014) Volta potential phase plate for in-focus phase contrast transmission electron microscopy. Proc Natl Acad Sci USA 111:15635-15640

Denkov ND, Velev OD, Kralchevsky PA, Ivanov IB, Yoshimura Y, Nagayama K (1992) Mechanism of formation of two-dimensional crystals from latex particles on substrates. Langmuir 8:3183-3190

Denkov ND, Velev OD, Kralchevsky PA, Ivanov IB, Yoshimura Y, Nagayama K (1993) Two-dimensional crystallization. Nature 361: 26-26

Dimitrov AS, Nagayama K (1996) Continuous convective assembling of fine particles into two-dimensional arrays on solid surfaces. Langmuir 12:1303-1311

Ernst RR, Anderson WA (1966) Application of Fourier transform spectroscopy to magnetic resonance. Rev Sci Instr 37:93-102

Fujiwara T, Nagayama K (1985) The wobbling-in-a-cone analysis of internal motion in macromolecules. J Chem Phys 83:3110-3117

Fujiwara T, Nagayama K (1988) Composite inversion pulses with frequency switching and their application to broadband decoupling. $\mathrm{J}$ Magn Reson 77:53-63

Fujiwara T, Nagayama K (1991) Numerical design of broadband composite pulses for quadrupole- echo experiments in $\mathrm{I}=1$ systems. $\mathrm{J}$ Magn Reson 93:563-571

Fujiwara T, Anai T, Kurihara N, Nagayama K (1993) Frequencyswitched composite pulses for decoupling of carbon-13 spins over ultrabroad bandwidths. J Magn Reson 104:103-105

Fukuda Y, Nagayama K (2012) Zernike phase contrast cryo-electron tomography of whole mounted frozen cells. J Struct Biol 177: 484-489

Hama K (1959) Some observations on the fine structure of the Giant nerve fibers of the earthworm, Eisenia foetida. J Biophys and Biochem Cytol 6:61-66

Hosokawa F, Danev R, Arai Y, Nagayama K (2005) Transfer doublet and an elaborated phase plate holder for $120 \mathrm{kV}$ Electron-phase microscope. J Electr Microsc 54:317-324

Iijima H, Fukuda Y, Arai Y, Terakawa S, Yamamoto N, Nagayama K (2014) Hybrid fluorescence and electron cryo-microscopy for simultaneous electron and photon imaging. J Struct Biol 185:107-115

Kaneko Y, Danev R, Nitta N, Nagayama K (2005) In vivo subcellular ultrastructures recognized with Hilbert-differential-contrast transmission electron microscopy. J Electr Microsc 54:79-84

Kaneko Y, Danev R, Nagayama K, Nakamoto H (2006) Intact carboxysomes in a cyanobacterial cell visualized by Hilbert 
differential contrast transmission electron microscopy. J Bacterol 188:805-808

Kralchevsky PA, Nagayama K (1994) Capillary forces between colloidal particles. Langmuir 10:23-36

Kralchevsky PA, Paunov VN, Ivanov IB, Nagayama K (1992) Capillary meniscus interaction between colloidal particles attached to a liquidfluid Interface. J Coll Interface Sci 151:79-94

Nagatani Y, Nagayama K (2011) Complex observation in electron microscopy VII: iterative phase retrieval for strong-phase objects by plural Hilbert differential contrast experiments. J Phys Soc Jpn 80: 094402-1-094402-8

Nagayama K (1979) Spin decoupling in two-dimensional J-resolved NMR spectroscopy. J Chem Phys 71:4404-4415

Nagayama K (1999) Complex observation in electron microscopy. I Basic scheme to surpass the Scherzer Limit. J Phys Soc Jpn 68: $811-822$

Nagayama K (2020) Four-dimensional electron microscopy renovated on Wigner optics, to be submitted

Nagayama K, Wada A (1972) $220 \mathrm{MHz}$ PMR of monodisperse PBLG at the helix-coil transition region. Chem Phys Lett 16:50-51

Nagayama K, Wüthrich K (1981) Systematic application of two- dimensional 1H NMR techniques for studies of proteins: combined use of spin echo correlated spectroscopy and J-resolved spectroscopy for the identification of complete spin systems of non-labile protons in amino acid residues. Eur J Biochem 114:365-374

Nagayama K, Wüthrich K, Bachmann P, Ernst RR (1977) Twodimensional J-resolved $1 \mathrm{H}$ n.m.r. spectroscopy for studies of biological macromolecules. Biochem Biophys Res Commun 78:99105

Nagayama K, Bachmann P, Wüthrich K, Ernst RR (1978) Use of crosssections and projections in two-dimensional NMR spectroscopy. J Magn Reson 31:133-148

Nagayama K, Wüthrich K, Ernst R (1979) Two-dimensional spin echo correlated spectroscopy (SECSY) for 1H NMR studies of biological macromolecules. Biochem Biophys Res Commun 90:305-311

Nagayama K, Kumar A, Wüthrich K, Ernst RR (1980) Experimental techniques of two-dimensional correlated spectroscopy. J Magn Reson 40:321-334

Nagayama K, Kobayashi Y, Kyogoku Y (1983) Difference techniques to pick up cross-peaks and suppress auto- peaks in two-dimensional shift-correlated and two-dimensional exchange NMR spectroscopies. J Magn Reson 51:84-94

Nagayama K, Yamazaki T, Yoshida M, Kanaya S, Nakamura H (1990) Combination of heteronuclear ${ }^{1} \mathrm{H}_{-}{ }^{15} \mathrm{~N}$ and ${ }^{1} \mathrm{H}-{ }^{13} \mathrm{C}$ threedimensional nuclear magnetic resonance experiments for amidedirected sequential assignment in larger proteins. J Biochem 108: $149-152$

Nagayama K, Onuma T, Ueno R, Tamehiro K, Minoda H (2016) Cathodoluminescence and electron-induced fluorescence enhancement of enhanced green fluorescent protein. J Phys Chem B 120(6):1169-1174

News \& Views (1973) The missing magnitudes. Nature 243:186-187

Research Highlights (2019) How to improve a huge super-resolution microscope: shrink it. Nature 574:456-456

Rochat RH, Liu X, Murata K, Nagayama K, Rixon F, Chiu W (2011) Seeing the portal in herpes simplex virus type 1B Capsids. J Virology 85:1871-1874

Sannomiya T, Arai Y, Nagayama K, Nagatani Y (2019) Transmission electron microscope using a linear accelerator. Phys Rev Lett 123: $150801-1 \sim 150,801-5$

Shimada A, Niwa H, Tsujita K, Suetsugu S, Nitta K, Hanawa-Suetsugu K, Akasaka R, Nishino Y, Toyama M, Chen L, Liu Z, Wang B, Yamamoto M, Terada T, Miyazawa A, Tanaka A, Sugano S, Shirouzu M, Nagayama K, Takenawa T, Yokoyama S (2007) Curved EFC/F-BAR- domain dimers are joined end to end into a filament for membrane invagination in endocytosis. Cell 129:761772

Toyo-oka T, Umeda M, Eguchi K, Nagayama K, Hosoda S (1986) Rhythmic change of myocardial phosphate metabolite content in cardiac cycle observed by depth-selected and EKG-gated in vivo 31P-NMR spectroscopy in a whole animal. Biochem Biophys Res Commun 135:808-815

Toyo-oka T, Nagayama K, Umeda M, Ogawa S, Eguchi K, Hosoda S, Sugimoto T (1987) Combined study of $1 \mathrm{H}$-magnetic resonance imaging and depth-selected EKG gated ${ }^{31} \mathrm{P}$-magnetic resonance spectroscopy of the heart in vivo. Biochem Biophys Res Commun 144: 841-848

Yamaguchi M, Danev R, Nishiyama K, Sugawara K, Nagayama K (2008) Zernike phase contrast electron microscopy of ice-embedded influenza A virus. J Struct Biol 162:271-276

Yamazaki T, Yoshida M, Kanaya S, Nakamura H, Nagayama K (1991) Assignments of backbone ${ }^{1} \mathrm{H},{ }^{13} \mathrm{C}$, and ${ }^{15} \mathrm{~N}$ resonances and secondary structure of ribonuclease $\mathrm{H}$ from Escherichia coli by heteronuclear three-dimensional NMR spectroscopy. Biochemistry 30:6036-6047

Yamazaki T, Yoshida M, Nagayama K (1993) Complete assignments of magnetic resonances of ribonuclease $\mathrm{H}$ from Escherichia coli by double- and triple-resonance 2D and 3D NMR spectroscopies. Biochemistry 32:5656-5669

Yoshimura Y, Endo S, Matsumoto M, Nagayama K (1990) Twodimensional crystallization of proteins on mercury. Ultramicroscopy 32:265-274

Publisher's note Springer Nature remains neutral with regard to jurisdictional claims in published maps and institutional affiliations. 